\title{
1. Entrepreneurship and psychology in geographic context: introduction
}

\subsection{BACKGROUND}

A vivid start-up culture - this is the common response one hears around the globe today when discussing key goals for regional development with policymakers, educators, business leaders, venture capitalists and entrepreneurs. While often cited examples for particularly successful start-up hubs are Silicon Valley and the Bay Area, Tel Aviv, London, Bangalore, Berlin and São Paulo, a vivid start-up culture is not only on the policy agenda of megacities and economic powerhouses; it represents an omnipresent policy target for all kinds of regions, cities and places (OECD 2020). But what is a vivid start-up culture? What are its key components? Can it be developed or is it simply a by-product of regional wealth and economic characteristics? And what is the people side of a vivid start-up culture? This book is devoted to these questions. Specifically, it attempts to make a contribution by addressing these questions from the perspective of geographical psychology. The existing research evidence, and the variety of new implications for entrepreneurship research, practice and policy, give rise to the foundation and definition of a new interdisciplinary research field - the geography of entrepreneurial psychology. This book gives an overview of the current state of this research and its implications. 
What is entrepreneurship? The many definitions often have a common core - behaviors such as being proactive, taking risks and creating something new, often motivated by a desire of self-realization and autonomy. While such behaviors can be found in all kinds of organizational contexts, most of the empirical research on entrepreneurship focuses on the formation of new businesses, which can be an important driver of economic development (Davidsson 2016b; Fritsch 2013; OECD 2020).

Because entrepreneurship is about certain behaviors, psychology as an academic discipline plays a key role - together with economics, management, sociology and geography - to name just the main disciplines involved in the interdisciplinary endeavor that is contemporary entrepreneurship research (Landström 2020). Economics, management and sociology deal particularly with incentives for different kinds of entrepreneurship and its effects. Geography is involved because regional conditions and dynamics drive various kinds of economic activities and outcomes (Fujita and Krugman 2004). This includes entrepreneurship, which is also regarded as a "regional event" (Feldman 2001) - something that is enabled by the interplay between different local factors in a given place or region (OECD 2020).

\subsection{ENTREPRENEURSHIP ACROSS SPACE}

Taking new business formation as an indicator of entrepreneurship, the number of start-ups or of people who are involved in the creation of a new venture shows tremendous geographical variation. There are sizeable differences in the levels of entrepreneurship across countries and such differences are even larger between the regions or places within a country. Variation of entrepreneurship across countries can have many reasons such as respective differences in formal institutions that tend to apply nationwide, whereas the deter- 
minants of regional differences within a country are more place-specific. Quite regularly, the variation of these regional conditions within countries is considerably larger than their variation between countries, indicating their important role.

Cities as a regional unit deserve special attention (Glaeser 2011). City size and population density represent a diversity of important influences on entrepreneurship such as availability of inputs (e.g., labor and finance), proximity to competitors on input and output markets, as well as price levels. Since R\&D activities of private firms, universities and other public research institutions tend to be located in larger cities, number of population and density in a region also indicate the availability of knowledge spillovers. Density is, however, also closely related to agglomeration diseconomies such as congestion, high cost of living, unfavorable environmental conditions and crime (Sternberg 2009).

Recent research has also identified an important role of a region's history on its level of entrepreneurship (Fritsch and Wyrwich 2019; Glaeser et al. 2015). The empirical evidence suggests that a region's history can lead to certain informal institutions (North 1994; Williamson 2000) that tend to be long-lasting. Due to such effects of historical factors, regions tend to follow specific development trajectories.

Economists and economic geographers have made a distinction between hard and soft factors that may contribute to the observed geographic heterogeneity in entrepreneurial activity and to the developmental trajectories of regions. The hard factors, which are relatively easy to measure, comprise, for example, the legal framework and public policy, age structure and qualification of the workforce, industry structure and density of economic activities (Bosma 2013; Sternberg 2009). Particularly important effects on regional entrepreneurial activity have been found for the size structure and the industry structure of the local economy. Based on the empirical finding that the largest share of founders has worked in small (vs. larger) firms before starting an own venture, the small firm 
sector is characterized as a seedbed for regional entrepreneurship (Fritsch and Falck 2007; Parker 2004). While regions with a large employment share in small firms tend to have relatively many start-ups, the opposite is found for places that are dominated by large-scale industries such as mining and steel (Stuetzer et al. 2016). Industry structure influences the qualifications and skills of the regional population that can affect entrepreneurial intentions and the prospects of start-ups.

While information on hard factors is often provided by official statistics, soft factors are more or less guesswork (Marshall 1920) so that their measurement is difficult and often incomplete. Many economists and economic geographers agree, however, that soft factors are particularly important for entrepreneurship, making them a promising and interesting research subject (Audretsch et al. 2019; Fritsch and Storey 2014; Saxenian 1996). There is, however, no consensus on how one can conceptualize and measure them. The respective literature often uses relatively loosely defined terms for the description of soft factors such as culture, history and traditions, or regional images. However, these terms may not deliver sufficiently concrete implications for entrepreneurship research and practice, or for public policy aiming to develop regional entrepreneurship.

Hence, while empirical research has resulted in a solid set of hard factors that tend to influence entrepreneurship in terms of new business formation, the effect of the soft factors is much less clear. In fact, the systematic investigation of relevant soft factors has become one of the major research goals in contemporary economics and economic geography. For example, while many experts seem to agree that local culture is important for regional entrepreneurship (e.g., OECD 2020), the term is extremely abstract and non-tangible - a black box for researchers, practitioners and policymakers alike.

So how can one investigate soft factors systematically, if they are that important? Most research in this field seems to agree that it is important to understand the people side of local 
mechanisms driving entrepreneurship. Among the different approaches from various disciplines that offer systematic concepts and analytical frameworks for investigating this people side, geographical psychology has become a promising and fruitful scholarly lens to conceptualize and measure some of the soft factors behind regional entrepreneurship.

In the following, we give a brief overview over the field of geographical psychology and how it is imbedded in the wider discipline of psychology.

\subsection{CONNECTING SPACE AND PSYCHOLOGY: GEOGRAPHICAL PSYCHOLOGY}

While psychological science has a traditional focus on intrapsychic processes (by examining what many in the wider public would typically regard as "psychological"), there is also a remarkably strong interest in context in contemporary psychological science. Relevant contexts can be very proximal to the individual (e.g., the immediate social and physical environment with which the individual directly interacts on a regular basis, such as the social and physical components of the family, friends/peers, work and leisure contexts). Other relevant contexts that are more distal to the individual, such as local and national institutions, also matter, often by shaping the more proximal contexts.

Across the life-span, people are situated in, and interact with, various contexts and levels of contexts, which can interact with others and change over time (Bronfenbrenner 1979). For example, people are selected into contexts (e.g., as function of normative age-correlated processes or of historical influences and changes in the macro-context) (Baltes et al. 2007). But people are not just passive; they are also active agents in their own development (Bandura et al. 1999), for example by proactively selecting, using and shaping contexts (Baltes and Baltes 2014; Lerner 1982). 
Even biological perspectives in psychology (e.g., behavioral genetics; see Plomin et al. 2003) take context very seriously, not only because people with their dispositions interact with the environment and many psychosocial outcomes can be understood as a product of gene-environment interactions (Moffitt et al. 2005; Ullen et al. 2016), but also because the environment can even affect biological levels of mind and behavior in a deeper way (Gottlieb 2003). For example, advances in the field of epigenetics have demonstrated that environmental and psychosocial factors can change the epigenome, and some studies have even showed that this can also be potentially transmitted to more than one generation of descendants. Hence, the environment has the potential to change the effect of genes (e.g., their expression in mind and behavior) not just for one generation, but for future descendant generations that might no longer be exposed to this environment (Jones et al. 2018; Masterpasqua 2009).

It is thus almost impossible to separate biology and environment in psychology (Rutter 2006). In other words, if biology (e.g., genes) is an essential component of mind and behavior, this also applies to the environment, and particularly to the interaction and transaction between biology and the environment, often mediated via human agency. This makes clear that a context-minded perspective matters to virtually all topics and fields of psychology. Psychological sciences have thus benefited from overlap and interdisciplinary exchange with adjacent fields such as sociology and biological ecology. Another field that is a less obvious partner for psychological research interested in context is human geography (Fouberg and Murphy 2020; Gregory and Walford 2016).

The scholarly field of human geography studies the interrelations between people, place and environment, considering particularly spatial and temporal factors of locations. Whereas physical geography focuses more on spatial aspects and mechanisms of the natural world, human geography is more interested in people, and the spatial organization and processes 
shaping their interactions with social and physical contexts. Ideas and insights from human geography have inspired and informed psychological science in a way that we have witnessed the emergence of the new subfield of geographical psychology, which is explicitly embracing the geographical perspective.

Broadly speaking, a geographical perspective to psychology applies a context perspective to psychology by taking the objective nature of the context seriously (instead of mere personal perceptions) - the geographical feature of the context itself, e.g., what defines a place or a region in terms of space. It is thus very different from inward-looking psychological science that emphasizes subjective perceptions and intrapsychic processes, e.g., how people think and decide. Geographical psychology is embedded in socioecological perspectives in psychology (see Oishi and Graham 2010), where the broader focus is on social ecology comprised of both physical and human environments.

Rentfrow and Jokela (2016) define geographical psychology as a research field that "aims to integrate psychology and the different levels of geographic analysis by focusing on the spatial distribution of psychological phenomena and their relations to features of the macro environment" (p. 393). Importantly, they see geographical psychology as linked yet independent of cross-cultural psychology. They stress that "both are concerned with connections between psychological phenomena and the broader environment" (p. 393), but "cross-cultural psychology focuses on connections between psychological phenomena and cultural symbols, practices, and norms without focusing specifically on geographic distributions" (p. 393). In contrast, "geographical psychology seeks to discover and understand the spatial organization of psychological phenomena and how that organization relates to individual behavior and the macro environment" (p. 393). Hence, geographical psychology puts a strong focus on a spatial component - how psychological factors and mechanisms (human 
behaviors and mindsets) vary and function across places and regions, as well as within and across different regional levels more broadly. This geographic component is fundamental, for example, in economic geography.

\subsection{THE GEOGRAPHY OF ENTREPRENEURIAL PSYCHOLOGY: A DEFINITION}

Drawing from the definition of geographical psychology (Rentfrow and Jokela 2016), the field of the geography of entrepreneurial psychology can be defined as the scholarly examination of the spatial organization of psychological phenomena associated with entrepreneurship. The research field is therefore located at the intersection between psychology, geography, economics and sociology. It puts a special focus on perspectives in geographical psychology and economic geography.

The field uses concepts, constructs and empirical insights from micro-level psychology (e.g., individual-level personality research) to develop and measure concepts and constructs at the aggregate geographical level. The micro-foundations of the macro-level focus in the geography of entrepreneurial psychology draw from various subdisciplines of psychology such as personality psychology, social psychology, work psychology/organization behavior, developmental psychology, biological psychology, health psychology and cognitive psychology. The field also integrates various approaches from economics and economic geography (e.g., spatial economic dynamics, cultural economics and economic history).

Starting with micro-level theories and concepts to understand and examine a macro-level phenomenon is not only a common strategy in geographical psychology (Rentfrow and Jokela 2016) but also in economics. In fact, the core of an economic approach to the social sciences is at the micro-level of individual behavior (Becker 1976; Kirchgässner 2008). 
Economics regards this individual behavior as the result of rational decisions based on utility considerations and commonly applies these micro-level theories to the explanation to aggregate behavior at the macro-level (e.g., consumption theory, theory of investment). The central idea of this individualistic method is that all macro-phenomena can be traced back to micro-behavior so that there is no basic ontological difference between these two levels.

It is also important to note that the field of the geography of entrepreneurial psychology overlaps with perspectives in culture research in entrepreneurship (Beugelsdijk and Smeets 2008; Davidsson 1995; Hayton and Cacciotti 2013; Stephan and Uhlaner 2010). However, it is different from cross-cultural psychological approaches insofar as "cross-cultural psychology focuses on connections between psychological phenomena and cultural symbols, practices, and norms without focusing specifically on spatial distributions (Oishi and Graham 2010; Rozin 2003). In contrast, geographical psychology seeks to discover and understand the spatial organization of psychological phenomena and how that organization relates to individual behavior and the macro environment" (Rentfrow and Jokela 2016, p. 393). Hence, research on the geography of entrepreneurial psychology can contribute to our understanding of an entrepreneurial culture but it should not be equated with culture research (Hofstede and McCrae 2004).

\subsection{PURPOSE OF THE BOOK}

This book provides an introduction into the geography of entrepreneurial psychology as an emerging field of research. Chapter 2 gives an overview of the micro-level psychology of entrepreneurship that provides the micro-foundations of the geography of entrepreneurial psychology. Chapter 3 then turns to empirical work on the macro-phenomenon of the psychology of entrepreneurship - the geographic variation 
of psychological factors associated with entrepreneurship. In Chapter 4 we discuss the phenomenon of regional levels of new venture creation and self-employment that have often been found to be rather persistent over long periods of time despite disruptive events such as devastating wars, several decades of socialist regime that followed anti-entrepreneurial policies, or even a nearly complete exchange of the local population. This in turn has important implications for the geography of entrepreneurial psychology and vice versa.

Chapter 5 surveys research on historical origins of regional differences in regional psychological factors, including the historical local exploitation of natural resources, as well as historical political and economic institutions. Chapter 6 discusses implications for practice, education and policy, and Chapter 7 proposes an extended agenda for future research on the topic. Chapter 8 provides a final summary and outlook. 